\title{
NEW GREAT HORNED OWL LONGEVITY RECORD
}

ROBERT W. NERO, Box 14, 1495 St. James Street, Winnipeg, Manitoba. R3H OW9

Avian longevity records based on banded bird returns in the files of the U.S. Bird Banding Laboratory, Laurel, Maryland, have been compiled and published several times, the most recent update appearing in $1989 .^{1}$ The oldest record given for a Great Horned Owl is 20 years, 7 months. That bird, banded by $\mathrm{C}$. Stuart Houston (who else?) on 20 May 1967 as a nestling near Elstow, Saskatchewan, was found dead on 18 January 1988 at Saskatoon.'

An injured, banded Great Horned Owl found on the grounds of the Assiniboine Park Zoo in Winnipeg on 6 January 1992 extends the longevity record by several years. Zookeeper Jacquie Randall, a volunteer wildlife rehabilitator, found the owl moving about with difficulty on the ground not far from Corydon Avenue. She obtained a net and attempted to capture the bird but it managed to fly up onto the roof of the Tropical House. An hour later, Jacquie found the bird back on the snow-covered ground and was able to capture it. She took the bird to the zoo hospital where it was examined by Dr. Gordon Glover and Janis McCarthy, both members of the Manitoba Wildlife Rehabilitation Organization. They concluded that the bird, noticeably thin and in a weakened condition, had been in collision with a moving vehicle. The nature of its injuries - chiefly a fractured orbital bone and a grossly dis- tended eyeball - led them to euthanize the bird.

Because the bird was banded, contact was made with Garth Ball, Manitoba Wildlife Branch. Through contacts in Ottawa, Ball discovered that the band (No. 568-17752) had been reported by band permittee Harold V. Hosford as having been placed on a Great Horned Owl on 20 December 1964. Hosford, now in retirement in Victoria, B. C., then lived at 4116 Roblin Boulevard, not far from where the bird was found. Hosford indicated that the bird had been captured nearby by Matt Dedrick. Dedrick remembered the incident well and within a few days brought his field notebook to me. This bird had been captured overnight in a drop-trap baited with a live pigeon in Dedrick's backyard at 669 Fairmont Road, just a few blocks from Hosford's former home.

The bird was removed from the trap on the morning of 20 December 1964 and taken to Hosford's house for banding. Hosford was away, but a band from his series was placed on the bird and it was then released. Dedrick's notes include mention of this bird being a "small to medium adult female." Judging by his detailed notes and comments, there had been no noticeable colour change in the plumage of this bird. The bird weighed "3.9 pounds" when 
captured. Interestingly, the same bird was recaptured in the same trap in Dedrick's backyard on 24 December 1966. Its weight then was recorded as " $41 / 4$ pounds."

If this bird was hatched in summer 1963, which would mean it was an adult when first captured on $20 \mathrm{De}$ cember 1964, then it would have been 28 years in summer 1991. Its minimum estimated age when captured on 6 January 1992 would therefore be 28 years, 7 months. It is possible that it was even older.

There is something appealing in contemplating the existence of a bird in the wild beyond the usual life span. So many things can happen to a bird. The survival of one owl for 28 years is impressive. This one record shows the potential - if all goes well. That this individual should have maintained itself in an urban environment is perhaps especially remarkable. Great Horned Owls are known to have nested in Assiniboine Park, so this bird could have been on its nesting territory. Clearly, if adequate habitat is preserved or developed, the urban setting can provide room for raptors.

1. KLIMKIEWICZ, M.K. and A.G. FUTCHER. 1989. Longevity records of North American birds. Supplement No. 1. J. of Field Ornithol. 60:469-494

\title{
NOTICE
}

\section{REQUEST FOR REPRINTS ON OWLS}

Authors of articles or publications dealing with owls and wishing them to be listed in the second edition of a Working Bibliography of Ow/s of the World are asked to send reprints to:

\author{
Richard J. Clark \\ The Owl Bibliography \\ c/o Department of Biology \\ York College of Pennsylvania \\ York, PA USA \\ 17405-7199
}

